\title{
Effects of Photosynthetically Active Radiation on Vegetative Growth of Texas Wild Rice and Consequences for Population Augmentation
}

\author{
Michele L. Crawford and Paula S. Williamson \\ Department of Biology, Texas State University, San Marcos, TX 78666
}

\author{
Tina M. Waliczek \\ Department of Agriculture, Texas State University, San Marcos, TX 78666 \\ David E. Lemke and Thomas B. Hardy \\ Department of Biology, Texas State University, San Marcos, TX 78666
}

Additional index words. exotic, invasive species, native plants, reintroduction, wildlife habitat

\begin{abstract}
As urbanization and urban sprawl increases, habitat for native flora and fauna often becomes threatened. Reestablishing wildlife habitats within designed landscapes has become increasingly popular with horticultural consumers, who are becoming more aware of the benefits of using native plants and the threats of invasive species. Texas wild rice (Zizania texana Hitchc.) is a federally endangered aquatic plant known to occur only in the San Marcos River, Hays County, TX. The objective of this study was to experimentally test the impact of light availability on the vegetative growth of Texas wild rice (TWR) ex situ. The effect of photosynthetically active radiation $(P A R)$ was tested by establishing treatment and control groups of plants in a river raceway located on the campus of Texas State University, San Marcos, TX. At the onset of the experiment, baseline growth data were collected on a random sample of 15 plants to determine starting conditions. The $\mathbf{7 5}$ plants within the control and treatment groups were also randomly selected. Two sequential experimental trials were designed involving the same treatment of $P A R$ reductions with 15 TWR plants in the control group $(100 \%$ of ambient $P A R$ conditions) and 15 within each of four experimental treatment units. Treatments included a reduction in ambient light values at each of the following rates: $P A R$ reduced by $10 \%$ (90\% ambient light), $20 \%$ (80\% ambient light), $40 \%$ (60\% ambient light), and $80 \%(20 \%$ ambient light). Results of the study indicated high shade areas contained reduced areal coverage or complete lack of TWR. There was a significant decrease in both above and below ground biomass, with an $80 \%$ reduction in available $P A R(20 \%$ available ambient light), and other growth parameters of TWR were negatively impacted by reductions in $P A R$ greater than $40 \%(60 \%$ ambient light availability) during the short-term early establishment growth period. Therefore, light availability is a critical environmental factor that must be given consideration when deciding areas of the river to plant TWR for population augmentation.
\end{abstract}

Very few ecosystems in the world are completely free of introduced species, and an increasing proportion of habitats are becoming dominated by them (Pysek and Richardson, 2010). Invasive species decrease species diversity (McGeoch et al., 2010), have negative economic impact (Pimentel et al., 2005), and threaten human health (Mack et al., 2000). Most nonnative plant introductions in the United States were imported for use in the landscape industry (Reichard, 1996). In recent years, horticulturists

Received for publication 22 Jan. 2020. Accepted for publication 10 Mar. 2020.

Published online 17 June 2020

T.M.W. is the corresponding author. E-mail: tc10@txstate.edu.

This is an open access article distributed under the CC BY-NC-ND license (https://creativecommons. org/licenses/by-nc-nd/4.0/). troduction attempts have failed (Godefroid et al., 2011; Seddon et al., 2007). However, Albrecht et al. (2011) point out that success rates are improving as we learn more about the science of reintroduction. Persistence of a reintroduced population is dependent on habitat conditions (Armstrong and Seddon, 2007). While reintroduction success relies on selection of appropriate habitat on a larger scale, population augmentation may be more nuanced. Falk et al. (1996) define augmentation as addition of individuals to an existing population to increase population size or genetic diversity. In the special case of augmentation, the habitat is assumed to be appropriate because the species already occurs at the site. However, within the site there can be subtle environmental differences that would influence establishment success.

Texas wild rice (Zizania texana Hitchc.) is a federally endangered aquatic plant known to occur only in the San Marcos River, Hays County, TX (USFWS, 1978). The enactment of a habitat conservation plan in 2012 placed priority on the recovery and sustainability of Texas wild rice (TWR) and established a goal of maintaining a minimum of $3550 \mathrm{~m}^{2}$ areal coverage of TWR in Spring Lake and the upper reaches of the river (Edwards Aquifer Recovery Implementation Program, 2012). Reaching the goal will likely rely on successful population augmentation.

In aquatic plants, a variety of abiotic factors including nutrients, water velocity, substrate type, and water temperature are known to influence growth and production (Bornette and Puijalon, 2011). Availability and intensity of light is also an important abiotic factor affecting aquatic plant growth (Case and Madsen, 2004; Kirk, 1994). A decrease in available $P A R$ can suppress the overall biomass production of macrophytes (Asaeda et al., 2004; Tóth, 2013). PAR availability is the factor most strongly correlated with the spatial coverage of aquatic plants (Davies-Colley and Nagels, 2008; Kirk, 1994).

Riparian shading or shading from adjacent macrophyte species may limit available light, resulting in reduced growth. Shading of Northern wild rice, Zizania palustris, by giant bur reed (Sparganium eurycarpum) was found to be the major cause of reduced wild rice yield (Clay and Oelke, 2017). PAR is also influenced by the extent of riparian shading, especially in relatively narrow rivers where light attenuation by the water column is minimal (Julian et al., 2008). The San Marcos River is relatively narrow, $5-15 \mathrm{~m}$ wide, and ranges from 1 to $4 \mathrm{~m}$ in depth (Terrell et al., 1978). Historically, TWR was reported residing in the upper reaches of the San Marcos River, its associated irrigation canals, and the headwaters of the river (Spring Lake) (Silveus, 1933). The current distribution of TWR is confined to the upper $5 \mathrm{~km}$ of the San Marcos River, with $97 \%$ of the population occurring in the upper $2.2 \mathrm{~km}$ (Wilson et al., 2017).

In studies conducted by Poole and Bowles (1999) and Tolman et al. (2014), it was 
suggested that TWR biomass production is in part related to the high river water clarity and spatial distribution in high incident light locations. Tolman (2013) examined the influence of velocity, depth, and light availability on the spatial distribution of TWR along three reaches in the upper portion of the San Marcos River. Tolman (2013) found the lowest areal coverage of TWR occurred in the narrowest segment of the river, with the greatest extent of riparian canopy cover. These areas were characterized as having reduced incident light reaching the water surface (i.e., greater than $80 \%$ shading) based on seasonal ray casting and canopy cover estimated from leaf on and leaf off densitometer readings at the water surface. The results of Tolman's study suggest that light may play a role in the distribution of TWR within the river; but it remains unclear how differential light availability may impact TWR production, or what levels of available PAR would be associated with decreased growth and fitness. Understanding the influence of PAR on growth of TWR may be critical in determining suitable locations for population augmentation.

The objective of this study was to experimentally test the impact of light availability on the vegetative growth of TWR ex situ. Because light availability may be an important determining factor governing the expansion of TWR in the river, results of this study will help guide future population augmentation and production of native and endangered plant efforts.

\section{Methods and Materials}

To test the effect of $P A R$ on the vegetative growth of TWR, an ex situ study was conducted in a raceway located on the campus of Texas State University, San Marcos, TX. We conducted two sequential experimental trials involving the same $P A R$ values. In each trial, we randomly assigned TWR plants to the control (100\% of ambient PAR conditions) or one of four experimental units where $P A R$ availability was 1) $90 \%$ ambient light, 2) $80 \%$ ambient light, 3) $60 \%$ ambient light, and 4) $20 \%$ ambient light.

For each of the two trials, we collected 120 tillers from $\approx 75$ TWR plants from the San Marcos River (Texas Parks and Wildlife permit \#INT 17 02-21b). We standardized tiller size by removing all but two stems from the plant and trimming the remaining two stems to $20 \mathrm{~cm}$ in length. We also removed all but five roots and trimmed those to $5 \mathrm{~mm}$ in length. We then placed the tillers at $3 \mathrm{~cm}$ depth into individual pots containing soil. We used a commercially purchased blend (50\% concrete sand and 50\% loam, with $0.64-\mathrm{cm}$ pea-size gravel spread on top of the mixture), which is used by the U.S. Fish and Wildlife Service San Marcos Aquatic Resource Center for TWR propagation. We placed the pots in the raceway, supplied by an artesian well. The source for the well is the Edwards Aquifer, which is also the source of the San Marcos River. The tillers grew for $30 \mathrm{~d}$ at
$100 \%$ ambient light. Upon completion of this baseline growth period, a random sample of 15 plants was harvested and growth data collected to determine starting conditions.

We then used 75 randomly selected TWR plants for each $P A R$ experimental trial. Plants were randomly assigned to the control $(100 \%$ ambient light) and $P A R$ reductions of 1) $10 \%$ (90\% ambient light), 2) 20\% (80\% ambient light), 3) 40\% (60\% ambient light), and 4) $80 \%$ (20\% ambient light). We used a randomized complete block design in which the control unit and experimental units were each $0.9 \mathrm{~m} \times 0.6 \mathrm{~m}$ in size. Fifteen plants were placed in the control, and 15 plants were placed in each experimental unit at a water depth of less than one meter. There were three replications per light regime. A replicate consisted of five plants, each in an individual pot containing the soil described above, placed in a plastic plant tray $(0.6 \mathrm{~m} \times$ $0.3 \mathrm{~m}$ ). To create the $P A R$ reductions we used two corner-placed, stacked cinder blocks (40 $\mathrm{cm} \times 20 \mathrm{~cm} \times 15 \mathrm{~cm}$ ) secured with nylon cable ties and affixed with a constructed PVC $(0.79 \mathrm{~cm}$ diameter $)$ shade frame $(1.21 \mathrm{~m} \times$ $0.9 \mathrm{~m}$ ) fitted with high-density polypropylene shadecloth and suspended above the surface of the water. We measured ambient PAR beneath the suspended shadecloth and above the water level using dual a channel LI-COR LI meter (1935A; Lincoln, NE) fitted with a $4 \pi$ sensor.

A submersible Tsunami pump (50PU.2.4S; Baru Balakong, Wilayah Persekutuan, Kuala Lumpur, Malaysia) $\left(0.04 \mathrm{~m}^{3} \cdot \mathrm{s}^{-1}\right)$ was positioned at the upstream end of each treatment unit to provide a consistent velocity of 0.2 to $0.4 \mathrm{~m} \cdot \mathrm{s}^{-1}$, which is within reported TWR suitability ranges (Saunders et al., 2001; Tolman, 2013; Tolman et al., 2014). Velocity at the upstream point of each treatment unit was determined using a Marsh-McBirney flow meter (2000; Frederick, MD) and top set wading rod.

We recorded water temperature and $\mathrm{pH}$ during the growing periods using YSI (85; Yellow Springs, OH) and Oakton (Con +6 ; Vernon Hills, IL) meters, respectively. We obtained daily percent cloud cover data from the San Marcos Airport weather station located $\approx 5 \mathrm{~km}$ from the study site (Weather Spark, 2020). There were some differences, although not significant $(\mathrm{F}=2.88 ; \mathrm{df}=2,209$; $\alpha=0.06$ ), in the average daily percent cloud cover for the two consecutive trials $(40 \%$ and $53 \%$, respectively). The artesian well provided constant water quality properties during the study, with a mean $\mathrm{pH}$ of 7.3 (trial 1) and 7.4 (trial 2) and a mean temperature of $22.4{ }^{\circ} \mathrm{C}$ (trial 1) and $22.3{ }^{\circ} \mathrm{C}$ (trial 2). Water temperature and $\mathrm{pH}$ in our study fell within reported ranges for the San Marcos River (Groeger et al., 1997). Dissolved oxygen (DO) in the upper San Marcos River fluctuates, with a mean of $7.6 \mathrm{mg} / \mathrm{L}$ ( $\mathrm{sD} 1.6 \mathrm{mg} / \mathrm{L}$ ), and water quality standards established for the San Marcos River by Texas Commission on Environmental Quality set DO at $6.0 \mathrm{mg} / \mathrm{L}$ minimum (The Meadows Center for Water and the Environment, 2013). Dissolved oxy- gen in our study was $6.5 \mathrm{mg} / \mathrm{L}$ (trial 2) and 6.9 $\mathrm{mg} / \mathrm{L}$ (trial 1).

Previous research documented that seasonally, recreational use of the river is highest in the summer, moderate in the fall, and lowest in winter and spring (CrawfordReynolds et al., 2016). Saunders et al. (2001) point out that recreational use of the river (resulting in increases in suspended sediment and turbidity, uprooting and physical damage to TWR stands, and submergence of reproductive culms from tubing, canoeing, kayaking, and swimming) presents challenges for the reintroduction, recovery, and management of TWR. The treatment periods in this study were selected to correspond with low levels of recreational activity in the San Marcos River, as this may be a desirable time to target transplants into the river in population augmentation attempts.

Trial 1's baseline period was 16 Dec. 2015 to 16 Jan. 2016, and its treatment growth period was 16 Jan. to 14 Feb. 2016. Trial 2's baseline period was 19 Feb. to 18 Mar. 2016, and its treatment growth period was 18 Mar. to 16 Apr. 2016.

At the end of the initial baseline period and treatment period, we removed surviving plants and placed them into an individual plastic bag for each treatment for transport to the laboratory. In the laboratory, we separated shoots from the root mass at the juncture. We recorded the number of individual roots (excluding root hairs) and leaves. We placed roots in a paper bag and dried them for $48 \mathrm{~h}$ at $60^{\circ} \mathrm{C}$ in a drying oven. We used a LICOR LI Portable Area meter (3000C; Lincoln, NE) to measure the leaf surface area of all leaves and placed shoots in a paper bag and dried them for $48 \mathrm{~h}$ at $60{ }^{\circ} \mathrm{C}$ in a drying oven. After drying, we weighed the shoots and roots to determine dry biomass $(\mathrm{g})$.

Cumulative hours of daylight in the trials were $642\left(5.8 \mathrm{~kW} / \mathrm{m}^{2}\right)$ in trial 1 and $701(8.7$ $\mathrm{kW} / \mathrm{m}^{2}$ ) in trial 2 (United States Naval Observatory, 2020). Because light duration changed seasonally, each trial was treated independently.

Data collected from the two trials were checked for assumptions of normality and homogeneity of variance. When necessary, data were $\log _{10}$ transformed to attain normality. TWR growth data including dry weight biomass, the ratio of above ground to below ground biomass, total biomass, shoot number, root number, and total leaf surface area were analyzed through a one-way analysis of variance (ANOVA). If the result was found to be significant, the ANOVA was followed by a pairwise comparison of means using Tukey's honestly significant difference test at a minimum level of $P<0.05$. All ANOVA and Tukey's honestly significant difference tests were performed using R 3.4.0 studio statistical analysis.

\section{Results and Discussion}

When compared with initial baseline, significant differences existed in growth data (Table 1). In trial 1, significantly greater 
Table 1. Results of ANOVA baseline and treatment values for shoot dry weight (SDW), root dry weight (RDW), above/below biomass (A/B), total biomass (TB), shoot number $(\mathrm{SN})$, root number $(\mathrm{RN})$, and total leaf surface area (TLSA) in the trials in the study of the effects of photosynthetically active radiation on vegetative growth of Texas wild rice.

\begin{tabular}{|c|c|c|c|c|c|c|c|}
\hline Trial 1 & F-value & $\mathrm{df}$ & $P$ & Trial 2 & F-value & $\mathrm{df}$ & $P$ \\
\hline$\overline{\mathrm{SDW}}$ & & & & SDW & & & \\
\hline Baseline & 5.05 & 5,84 & $<0.01$ & Baseline & 5.32 & 5,64 & $<0.01$ \\
\hline Treatment & 1.14 & 4,66 & 0.32 & Treatment & 2.58 & 4,54 & 0.05 \\
\hline RDW & & & & RDW & & & \\
\hline Baseline & 7.57 & 5,84 & $<0.00$ & Baseline & 3.60 & 5,64 & 0.01 \\
\hline Treatment & 4.14 & 4,70 & 0.01 & Treatment & 3.99 & 4,54 & 0.01 \\
\hline $\mathrm{A} / \mathrm{B}$ & & & & $\mathrm{A} / \mathrm{B}$ & & & \\
\hline Baseline & 1.28 & 5,84 & 0.28 & Baseline & 5.91 & 5,64 & $<0.01$ \\
\hline Treatment & 1.09 & 4,70 & 0.37 & Treatment & 3.51 & 4,54 & 0.01 \\
\hline $\mathrm{TB}$ & & & & $\mathrm{TB}$ & & & \\
\hline Baseline & 3.95 & 5,68 & $<0.01$ & Baseline & 6.49 & 5,79 & $<0.00$ \\
\hline Treatment & 2.40 & 4,54 & 0.05 & Treatment & 2.55 & 4,60 & 0.05 \\
\hline $\mathrm{SN}$ & & & & $\mathrm{SN}$ & & & \\
\hline Baseline & 4.93 & 5,84 & $<0.01$ & Baseline & 5.22 & 5,80 & $<0.01$ \\
\hline Treatment & 2.13 & 4,68 & 0.09 & Treatment & 2.89 & 4,54 & 0.03 \\
\hline $\mathrm{RN}$ & & & & $\mathrm{RN}$ & & & \\
\hline Baseline & 7.25 & 5,84 & $<0.00$ & Baseline & 5.56 & 5,67 & $<0.01$ \\
\hline Treatment & 2.73 & 4,70 & 0.04 & Treatment & 2.26 & 4,57 & 0.05 \\
\hline TLSA & & & & TLSA & & & \\
\hline Baseline & 4.93 & 5,84 & $<0.01$ & Baseline & 5.54 & 5,64 & $<0.01$ \\
\hline Treatment & 2.62 & 4,70 & 0.04 & Treatment & 2.46 & 4,54 & 0.05 \\
\hline
\end{tabular}

values were obtained for shoot biomass, root biomass, total biomass, shoot number, root number, and total leaf surface area. In trial 2, significantly greater values were obtained for shoot biomass, root biomass, above/below biomass, total biomass, shoot number, root number, and total leaf surface area. When compared with the baseline, a significant increase in growth was recorded at $80 \%$ ambient light, and a significant decrease in growth was noted at $20 \%$ ambient light in both trials (Table 1).

Significant differences in shoot biomass, root biomass, ratio of above/below ground biomass, total biomass, and shoot number were found as a function of $P A R$ level (Table 2). In trial 1, plants exposed to $20 \%$ ambient light exhibited significantly lower root biomass $(P=0.01)$, total biomass $(P=$ $0.03)$, and root number $(P=0.05)$ when compared with plants exposed to $80 \%$ ambient light (Table 1). Trial 2 plants exposed to $20 \%$ ambient light exhibited significantly lower root biomass $(P<0.01)$, shoot biomass $(P=0.02)$, total biomass $(P=0.03)$, root number $(P=0.05)$, shoot number $(P=0.03)$, and total leaf surface area $(P=0.02)$ when compared with plants exposed to $80 \%$ ambient light (Table 2). Additionally, plants exposed to $20 \%$ ambient light exhibited significantly lower root biomass $(P=0.04)$ in trial 1 and above/below ground biomass $(P=0.05)$ and shoot number $(P=0.02)$ in trial 2 when compared with $90 \%$ ambient light.

Decline in population size of Texas wild rice was noted by Emery in the 1960s. Emery (1967) cited several factors thought to have probable effect on the rapid decline of TWR in the upper portion of the San Marcos River, including river bottom dredging, floating vegetative debris, and sewage pollution. In a later assessment, Emery (1977) found that abatement of river bottom dredging had occurred along with regular collection of vegetative debris and upgrades in city sewage treatment facilities. However, the rate of decline had only slowed and had not resulted in the restoration of sexual reproduction or any appreciable increase in spatial coverage via clones. These observed declines and identified factors underpinned the decision to designate the taxon as an endangered species (USFWS, 1978).

Vaughan (1986) identified several additional factors suspected of affecting the distribution and abundance of TWR, including point and nonpoint source pollution, competition from introduced and native aquatic plant species, recreational use causing "knock-down" of inflorescences, and construction of dams causing a rise in the water level thus affecting growth and seed production. Factors such as altered sedimentation patterns, water depth and alteration in flow patterns due to the presence of dams, changes in sediment composition as a result of road and building construction, depletion of the seed bank by river bottom dredging and herbivory, and diminished spring flow related to groundwater pumping have also been suggested as influencing the distribution of TWR (Power, 1996).

Cessation of river bottom dredging and restoration efforts starting in the late 1980s resulted in measurable increases in spatial coverage (Poole, 2002). Recent restoration activities set forth in the Edwards Aquifer Recovery Implementation Program Habitat Conservation Plan (Edwards Aquifer Recovery Implementation Program, 2012) include establishment of protected areas, removal of invasive and nonnative aquatic plants, TWR augmentation, and increasing public awareness.

TWR population augmentation has previously been attempted within the San Marcos River. Poole (2002), while conducting a multiyear investigation mapping populations of TWR in the San Marcos River, noted 20 new stands appeared in 1997 in the upper segment of the river below Spring Lake Dam at the headwaters. Poole (2002) attributed this increase to augmentation by dispersal of $\approx 10,000$ TWR seeds in the summer of 1996 below Spring Lake Dam (Kathryn Kennedy of the U.S. Fish and Wildlife Service, personal communication). More recently, population augmentation by TWR planting has been shown to be successful (Hardy et al., 2016).

In the current study, we were most interested in the effect of ambient light on TWR plant growth over a short duration, as this would be a critical stage for transplant establishment supporting population augmentation. We found the greatest extent of growth in TWR occurred in plants exposed to $80 \%$ ambient light. Light availability is of major importance in determining aquatic plant production and distribution in the aquatic environment (Case and Madsen, 2004; Kirk, 1994). The availability of light in the aquatic environment may be impacted by factors such as the amount of incident radiation and back-reflectance at the water surface, optical properties within the water column, depth, turbidity from urbanization and recreational activity, and overhead shading due to riparian cover (Bornette and Puijalon, 2011; Kirk, 1994; Pedersen et al., 2013; Sculthorpe, 1967; Tolman, 2013).

Studies with aquatic macrophytes have shown that shoot biomass, root biomass, and shoot number decrease under conditions of reduced ambient light availability. Elodea canadensis, Myriophyllum spicatum, and Littorella uniflora showed a reduction in root biomass at lower ambient light levels (Abernethy et al., 1996; Sand-Jensen and Madsen, 1991; Søndergaard and Bonde, 1988). Clay and Oelke (2017) found a reduction in shoot dry weight in Zizania palustris, Northern wild rice, when plants were grown in a $47 \%$ shade treatment as compared with $100 \%$ ambient light. Kurtz et al. (2003) investigated the impact of light reduction in Vallisneria americana and found a significant reduction in root biomass, shoot biomass, and above/below biomass occurred 


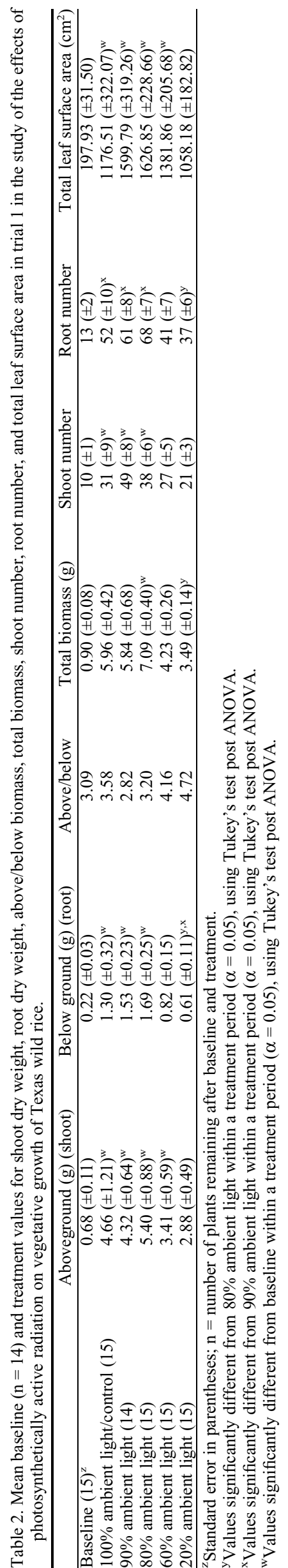

when plants were subjected to $21 \%$ and $8 \%$ ambient light. We found a similar result in that with $20 \%$ ambient light root biomass in both trials, shoot biomass (trial 2), and above/ below biomass (trial 2) of TWR were significantly reduced when compared with the $80 \%$ and $90 \%$ ambient light treatments. Barko and Smart (1981) found that Hydrilla, and to a lesser extent Myriophyllum, exhibited decreased shoot number with increasing shade. Similarly, TWR showed a significant decrease in shoot number at lower ambient light levels in trial 2.

Some plant species exhibit an increased leaf surface area when exposed to low light availability. Aleric and Kirkman (2005) investigated the growth response of the federally endangered terrestrial shrub Lindera melissifolia and found total leaf surface area to be greatest in $19 \%$ ambient light when compared with $58 \%$ and $100 \%$ ambient light. An increased leaf surface area allows greater interception of the little light that is available for photosynthesis. The opposite growth response was found in TWR, which exhibited a significant decrease in total plant leaf surface area at $20 \%$ ambient light in trial 2 . Longer experiments under a broader range of light conditions might reveal if TWR is capable of a compensatory response in leaf structure resulting from light reduction.

Although submersed aquatic macrophytes are considered to be shade tolerant (Best et al., 2001; Carr et al., 1997), their growth is impacted by limited light availability. $P A R$ availability is considered most strongly correlated with areal coverage of aquatic plants and is influenced by the extent of riparian shading (Davies-Colley and Nagels, 2008; Julian et al., 2008). In a survey conducted in 17 Florida streams, shading resulting from riparian vegetation was suggested to be a dominant factor in controlling the location and abundance of aquatic macrophytes (Canfield and Hoyer, 2011). Tolman (2013) found TWR to be spatially distributed in areas having greater sustained direct sunlight on an annual basis compared with shaded areas from the distribution and riparian canopy characteristics. High shade areas were found to contain reduced areal coverage or complete lack of TWR. Our study found a significant decrease in both above and below ground biomass with an $80 \%$ reduction in available $P A R(20 \%$ available ambient light), and we found other growth parameters of TWR were negatively impacted by reductions in $P A R$ greater than $40 \%$ (60\% ambient light availability) during the short-term early establishment growth period. Additional research using long-term study periods are necessary to ascertain if the level of biomass reduction observed during short-term early growth would result in differential fitness for the plant.

The experimental design we used relied on $P A R$ reduction increments that doubled the reduction values. It is likely that the actual threshold of TWR growth response to $P A R$ reduction lies between $60 \%$ and $20 \%$ available ambient light values. Additional exper- iments should target $P A R$ reductions between $40 \%$ and $80 \%$ to better define the response point. It should be noted that the observed responses of TWR to $P A R$ reduction in these experiments were associated with water depths of less than a meter. Although testing response to depth was beyond the scope of the current study, it is reasonable to assume that the effect of $P A R$ reduction at the water surface would result in differential plant growth as a function of increasing water depth, due to light attenuation. Results of our study have specific management implications for TWR population augmentation. Light availability is a critical environmental factor that must be given consideration when deciding areas of the river to plant TWR for population augmentation.

Studies have found an increased preference among gardeners for native species (Kendel et al., 2012) and a greater awareness of the threat of invasive species across the world (Zagorski et al., 2004). Native species are recognized for their ease of growth, adaptability to heat, cold, soil and drought conditions, as well as their value to the overall regional and local ecosystems (Narango et al., 2017). In this time of increased urbanization, horticulturists are being called on to not only select and grow aesthetically appealing plants, but also those that will help support habitats (Fiedler and Landis, 2007). This study provided an example of a system and methodology for propagating and enhancing plant populations in a protected environment. Similar methods and considerations may be applied with native plant production and landscape introductions within horticultural nursery and design applications.

\section{Literature Cited}

Abernethy, V.J., M.R. Sabbatini, and K.J. Murphy. 1996. Response of Elodea canadensis Michx. and Myriophyllum spicatum L. to shade, cutting and competition in experimental culture. Hydrobiologia 340:219-224.

Albrecht, M.A., E.O. Guerrant, Jr., K. Kennedy, and J. Maschinski. 2011. A long-term view of rare plant reintroduction. Biol. Conserv. 144:25572558.

Aleric, K.M. and L.K. Kirkman. 2005. Growth and photosynthetic responses of the federally endangered shrub, Lindera melissifolia (Lauraceae), to varied light environments. Amer. J. Bot. 92:682-689.

Armstrong, D.P. and P.J. Seddon. 2007. Directions in reintroduction biology. Trends Ecol. Evol. 23:20-24.

Asaeda, T., M. Sultana, J. Manatunge, and T. Fujino. 2004. The effect of epiphytic algae on the growth and production of Potamogeton perfoliatus L. in two light conditions. Environ. Exp. Bot. 52:225-238.

Barko, J.W. and R.M. Smart. 1981. Comparative influences of light and temperature on the growth and metabolism of selected submersed freshwater macrophytes. Ecol. Monogr. 51:219-235.

Bell, C.E., C.A. Wilen, and A.E. Stanton. 2003. Invasive plants of horticultural origin. HortScience 38:14-16.

Best, E.P.H., C.P. Buzzell, S.M. Bartell, R.L Wetzel, W.A. Boyd, R.D. Doyle, and J.R. Campbell. 2001. Modeling submersed macrophyte growth in relation to underwater light 
climate: Modeling approaches and application potential. Hydrobiologia 444:43-70.

Bornette, G. and S. Puijalon. 2011. Response of aquatic plants to abiotic factors. Rev. Aquat. Sci. 73:1-14.

Canfield, D.E. and M.V. Hoyer. 2011. Influence of nutrient enrichment and light availability on the abundance of aquatic macrophytes in Florida streams. Can. J. Fish. Aquat. Sci. 45:14671472.

Carr, G.M., H.C. Duthie, and W.D. Taylor. 1997. Models of aquatic plant productivity: A review of the factors that influence growth. Aquat. Bot. 59:195-215.

Case, M.L. and J.D. Madsen. 2004. Factors limiting the growth of Stuckenia pectinate (sago pondweed) in Heron Lake, Minnesota. J. Freshwat. Ecol. 19:17-23.

Clay, S.A. and E.A. Oelke. 2017. Effects of giant bur reed (Sparganium eurycarpum) and shade on wild rice (Zizania palustris). Weed Sci. 35:640-646.

Crawford-Reynolds, M., O. Agare, K. Kollaus, P. Williamson, T. Hardy, and W. Nowlin. 2016. Suspended sediment impacts on Texas wild rice and other aquatic plant growth characteristics and aquatic macrophytes. Edwards Aquifer Authority. 20 Jan. 2020. <https:// www.edwardsaquifer.org/wp-content/uploads/ 2019/02/EAHCP_TWR_Invert_Turbidity_on_ TRACS_1_6_2017.pdf $>$.

Davies-Colley, R.J. and J.W. Nagels. 2008. Predicting light penetration into river waters. J. Geophysical Res.: Biogeosci. 113: (G3), CiteID G03028, doi: 03010.01029/02008JG000722.

Edwards Aquifer Recovery Implementation Program, Habitat Conservation Program. 2012. 12 Oct. RECON Environmental Inc, Hicks and Company, Zara Environmental LLC, and BIOWEST. Edwards Aquifer Authority, San Antonio, TX.

Emery, W.H.P. 1967. The decline and threatened extinction of Texas wild rice (Zizania texana Hitchc.). Southwest. Nat. 12:203-204.

Emery, W.H.P. 1977. Current status of Texas wild rice. Southwest. Nat. 22:393-394.

Falk, D.A., C. Millar, and P. Olwell. 1996. Restoring diversity: Strategies for reintroduction of endangered plants. Island Press, WA.

Fiedler, A.K. and D.A. Landis. 2007. Attractiveness of Michigan native plants to arthropod natural enemies and herbivores. Environ. Entomol. 36:751-765.

Godefroid, A., C. Piazza, G. Rossi, S. Buord, A.-D. Stevens, R. Aguraiuja, C. Cowell, C.W. Weekley, G. Vogg, J.M. Iriondo, I. Johnson, B. Dixon, D. Gordon, S. Magnanon, B. Valentin, K. Bjureke, R. Koopman, M. Vicens, M. Virevaire, and T. Vanderborgh. 2011. How successful are plant reintroductions? Biol. Conserv. 144:672-682.

Groeger, A.W., P.F. Brown, T.E. Tietjen, and T.C. Kelsey. 1997. Water quality of the San Marcos River. Tex. J. Sci. 49:279-294.

Hardy, T., K. Kollaus, K. Tolman, T. Heard, and M. Howard. 2016. Ecohydraulics in applied river restoration: A case study in the San Marcos River, Texas, USA. J. Appl. Water Eng. and Res. 4:2-10.

Julian, J.P., M.W. Doyle, S.M. Powers, E.H. Stanley, and A. Riggsbee. 2008. Optical water quality in rivers. Water Resour. Res. 44:W10411, doi: 10.1029/2007WR006457.
Kendel, D., K.J.H. Williams, and N.S.G. Williams. 2012. Plant traits link people's plant preferences to the composition of their gardens. Landsc. Urban Plan. 105:34-42.

Kirk, J.T. 1994. Light and photosynthesis in aquatic ecosystems. 2nd ed. Cambridge Univ. Press, Cambridge, UK.

Kurtz, J.C., D.F. Yates, J.M. Macauley, and R.L. Quarles. 2003. Effects of light reduction on growth of the submerged macrophyte Vallisneria americana and the community of rootassociated heterotrophic bacteria. J. Exp. Mar. Biol. Ecol. 291:199-218.

Mack, R.N., D. Simberloff, W.M. Lonsdale, H. Evans, M. Clout, and F.A. Bazzaz. 2000. Biotic invasions: Causes, epidemiology, global consequences, and control. Ecol. Appl. 10:689710 .

McGeoch, M.A., S.H.M. Butchart, D. Spear, E. Marais, E.J. Kleynhans, A. Symes, J. Chanson, and M. Hoffmann. 2010. Global indicators of biological invasion: Species numbers, biodiversity impact and policy responses. Divers. Distrib. 16:95-108.

Oxley, F.M., T.M. Waliczek, and P.S. Williamson. 2016. Stakeholder opinions on invasive species and their management in the San Marcos River. HortTechnology 26:514-521.

Narango, D.L., D.W. Tallamy, and P. Marra. 2017. Native plants improve breeding and foraging habitat for an insectivorous bird. Biol. Conserv. 213:42-50.

Pedersen, O., T.D. Colmer, and K. Sand-Jensen. 2013. Underwater photosynthesis of submerged plants-Recent advances and methods. Frontiers in Plant Sci. 4:1-19.

Pemberton, H.B., T.D. Davis, M.A. Arnold, C. McKinney, L. Stein, D. Rodriguez, and R.D. Lineberger. 2014. Texas Superstar program: Using technology to promote the use of welladapted plants for landscapes in high temperature regions with limited water resources. J. Arid Land Studies 24:209-211.

Pimentel, D., R. Zuniga, and D. Morrison. 2005. Update on the environmental and economic costs associated with alien-invasive species in the United States. Ecol. Econ. 52:273-288.

Poole, J.M. 2002. Historical distribution of Texas wild rice (Zizania texana) from 1989-2001. Section 6. Final Report, p. 581. Texas Parks and Wildlife Department, Austin, TX.

Poole, J. and D.E. Bowles. 1999. Habitat characterization of Texas wild-rice (Zizania texana Hitchcock), an endangered aquatic macrophyte from the San Marcos River, TX, USA. Aquat. Conser. Marine and Freshwater Ecosystems 9:291-302.

Power, P. 1996. Effects of current velocity and substrate composition on growth of Texas wild rice (Zizania texana). Aquat. Bot. 55:199-204.

Pysek, P. and D.M. Richardson. 2010. Invasive species, environmental change and management, and health. Manag. Biol. Invasions 35:25-55.

Reichard, S.E. 1996. Prevention of invasive plant introductions on national and local levels, $\mathrm{p}$. 215-227. In: J.O. Luken and J.W. Thieret (eds.). Assessment and management of plant invasions. Springer-Verlag, New York.

Saunders, K.S., K.B. Mayes, T.A. Jurgensen, J.F. Trungale, L.J. Kleinsasser, K. Aziz, J.R. Fields, and R.E. Moss. 2001. An evaluation of spring flows to support the upper San Marcos River spring ecosystem, Hays County, Texas. River Studies Report No. 16. Resource Protection Division. Texas Parks and Wildlife Department, Austin, TX.

Sand-Jensen, K. and T.V. Madsen. 1991. Minimum light requirements of submerged freshwater macrophytes in laboratory growth experiments. J. Ecol. 79:749-764.

Sculthorpe, C.D. 1967. Biology of aquatic vascular plants. Edward Arnold, London.

Seddon, P.J., D.P. Armstrong, and R.F. Maloney. 2007. Developing the science of reintroduction. Conserv. Biol. 21:303-312.

Silveus, W.A. 1933. Texas grasses, classification and description of grasses. The Clegg Co., San Antonio, TX.

Søndergaard, M. and G. Bonde. 1988. Photosynthetic characteristics and pigment content and composition in Littorella uniflora (L.) Aschers. in a depth gradient. Aquat. Bot. 32:307319.

Terrell, E.E., W.H.P. Emery, and H.E. Beaty. 1978. Observations on Zizania texana (Texas wild rice), an endangered species. Bul. of the Torrey Bot. Club 105:50-57.

The Meadows Center for Water and the Environment. 2013. Upper San Marcos Watershed Data Report. Texas State University, San Marcos, TX.

Tolman, K. 2013. Habitat characterization of Zizania texana in the San Marcos River. Texas State University, San Marcos, TX, Master's Thesis.

Tolman, K., K. Kollaus, T. Heard, T. Hardy, J. Jensen, and N. Currit. 2014. Habitat suitability modeling of endangered Zizania texana, within a highly urbanized, artesian ecosystem in San Marcos, Texas. 10th International Symposium on Ecohydraulics, Trondheim, Norway.

Tóth, V.R. 2013. The effect of periphyton on the light environment and production of Potamogeton perfoliatus $\mathrm{L}$. in the mesotrophic basin of Lake Balatan. Aquat. Sci. 75:523-534.

United States Fish and Wildlife Service. 1978. Endangered and threatened wildlife and plants. Fed. Regist. 43:17910-17916.

United States Naval Observatory. 2020. Naval oceanography portal: Astronomical observations. 6 Apr. 2020. $<$ https://www.usno.navy.mil/ USNO/astronomical-applications $>$.

Vaughan, J.E., Jr. 1986. Population and autoecological assessment of Zizania texana, Hitchc. (Poaceae) in the San Marcos River. Southwest Texas State University, Master's Thesis, San Marcos, TX.

Waliczek, T.M., K. Parsley, P.S. Williamson, and F.M. Oxley. 2018. Curricula influence college student knowledge and attitudes regarding invasive species. HortTechnology 28:548-556.

Wasowski, S. and A. Wasowski. 1997. Native Texas plants landscaping region by region. Gulf Publ. Co., Houston, TX.

Weather Spark. 2020. 19 Jan. 2020. <https://weatherspark.com/y/7997/Average-Weather-in-San-MarcosTexas-United-States-Year-Round $>$.

Wilson, W.D., J.T. Hutchinson, and K.G. Ostrand 2017. Genetic diversity assessment of in situ and ex situ Texas wild rice (Zizania texana) populations, an endangered plant. Aquat. Biol. 136:212-219.

Zagorski, T., J.B. Kirkpatrick, and E. Stratford. 2004. Gardens and the bush: Gardeners' attitudes, garden types and invasives. Austral. Geogr. Stud. 42:207-220. 